\title{
Preoperative Vitamin D Level is Associated with Postoperative Delirium After Cardiac Surgery in Patients Over 65 Years of Age
}

\author{
Naim Boran Tumer, ${ }^{1}$ Atike Tekeli Kunt, ${ }^{2}$ Serdar Gunaydin, ${ }^{1}$ Kanat Ozisik ${ }^{1}$ \\ ${ }^{1}$ SBU Ankara City Hospital, Department of Cardiovascular Surgery, Ankara, Turkey; ${ }^{2}$ Kirikkale University Faculty of Medicine, \\ Department of Cardiovascular Surgery, Kirikkale, Turkey
}

\section{ABSTRACT}

Introduction: Delirium after cardiac surgery is a devastating and important complication. Delirium is defined as "disturbance in attention (i.e., reduced ability to direct, focus, sustain, and shift attention) and awareness (reduced orientation to the environment)." In this study, we analyzed the association of preoperative vitamin D levels and postoperative delirium after cardiac surgery in patients over 65 years.

Materials and methods: We retrospectively reviewed the data of 212 adult patients above 65 years of age who underwent isolated coronary artery bypass graft surgery from January 2016 to January 2018. The mean age for Group I was $69.7 \pm 7.4$ and Group II was $70.6 \pm 4.8$ years. There were 112 female patients in Group I and 46 female patients in Group II. The patient population was divided into 2 groups based on preoperative serum vitamin D (25-hydroxyvitamin D [25-OHD]) levels (normal range of $25-75 \mathrm{nmol} / \mathrm{L}$ ). Group I included patients with preoperative serum 25-OHD level $<25 \mathrm{nmol} / \mathrm{L}$. Group II included patients with preoperative serum 25-OHD level $\geq 25 \mathrm{nmol} / \mathrm{L}$.

Results: The incidence of delirium in this study was $30.2 \%$. In this study, 138 patients $(65.1 \%)$ had preoperative serum 25-OHD levels $<25 \mathrm{nmol} / \mathrm{L}$, and 74 patients (34.9\%) had preoperative serum $25-\mathrm{OHD}$ levels $\geq 25 \mathrm{nmol} / \mathrm{L}$. Preoperative serum 25-OHD levels were associated with postoperative delirium after coronary artery bypass graft surgery. Our retrospective study illustrated that a lower preoperative serum level of $25-\mathrm{OHD}$ was associated with postoperative delirium. Our results showed that $65.1 \%$ of patients had preoperative serum $25-\mathrm{OHD}$ levels $<25 \mathrm{nmol} / \mathrm{L}$, and this was associated with postoperative delirium.

Conclusion: Vitamin D deficiency exacerbates delirium after coronary artery bypass surgery with cardiopulmonary bypass. Whether the effects of vitamin $\mathrm{D}$ deficiency during this event represent separate or interrelated activities with cardiopulmonary bypass is an important question to address and prospective randomized studies are necessary to confirm these results.

Received March 12, 2020; received in revised form April 16, 2020; accepted April 18, 2020.

Correspondence: Naim Boran Tumer, SBU Ankara City Hospital, Ankara, Turkey; (e-mail: naimborantumer@hotmail.com)

\section{INTRODUCTION}

Delirium after cardiac surgery is a devastating and important complication. Diagnostic and Statistical Manual of Mental Disorders, fifth edition (DSM-5) defines delirium as "Disturbance in attention (i.e., reduced ability to direct, focus, sustain, and shift attention) and awareness (reduced orientation to the environment)" [European Delirium Association 2014]. Its incidence is suggested to be between 3\%-67\% [Gosselt 2015; Norkiene 2013], and it is highly prevalent in elderly patients [Grover 2012]. Many scales for both diagnosis and screening of delirium were reported [Grover 2012; Cropsey 2015]. CAM-ICU is a specific assessment tool for patients in ICU. It is an easy tool for assessment of delirium and takes only 1-2 minutes if performed by a trained physician or nurse without a need for a psychiatrist. Its sensitivity is $95 \%$ to $100 \%$ and its specificity is $93 \%$ to $98 \%$ [Grover 2012]. The mechanisms underlying delirium are multifactorial. The main risk factors of delirium after cardiac surgery are suggested to be age, cerebrovascular disease, type of surgery, transfusion of blood and blood products, atrial fibrillation, postoperative oxygen saturation, renal failure and mechanical ventilation time [Gosselt 2015]. Postoperative delirium is related to morbidities, such as prolonged mechanical ventilation, ICU and hospital stay times, sternal dehiscence and related mediastinitis and also

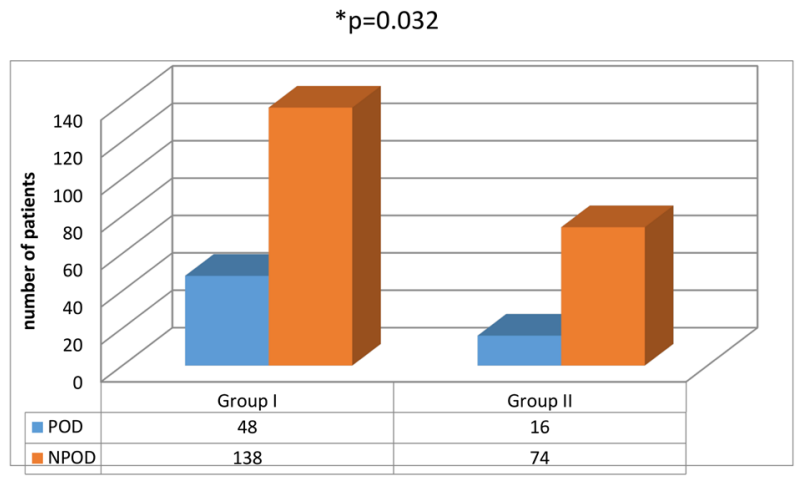

The rate of postoperative delirium in Group I and Group II Group I= patients with preoperative serum $25-\mathrm{OHD}$ levels $<25 \mathrm{nmol} / \mathrm{L}$, Group II= patients with preoperative serum $25-\mathrm{OHD}$ levels $\geq 25 \mathrm{nmol} / \mathrm{L}$. POD: Postoperative delirium NPOD: no postoperative delirium. $* P<.05$, statistically significant. 
Table 1. The Confusion Assessment Method for the Intensive Care Unit (CAM-ICU)*

\begin{tabular}{lc}
\hline Features and Descriptions & Pbsent \\
\hline
\end{tabular}

I. Acute onset or fluctuating course

A. Is there evidence of an acute change in mental status from the baseline?

B. Or, did the (abnormal) behavior fluctuate during the past 24 hours, that is, tend to come and go or increase and decrease in severity as evidenced by fluctuations on the Richmond Agitation Sedation Scale (RASS) or the Glasgow Coma Scale?

II. Inattention

Did the patient have difficulty focusing attention as evidenced by a score of less than 8 correct answers on either the visual or auditory components of the Attention Screening Examination (ASE)?

III. Disorganized thinking

Is there evidence of disorganized or incoherent thinking as evidenced by incorrect answers to 3 or more of the 4 questions and inability to follow the commands?

Questions

1. Will a stone float on water?

2. Are there fish in the sea?

3. Does 1-pound weight more than 2 pounds?

4. Can you use a hammer to pound a nail?

Commands

1. Are you having unclear thinking?

2. Hold up these many fingers. (Examiner holds 2 fingers in front of the patient.)

3. Now do the same thing with the other hand (without holding the 2 fingers in front of the patient).

(If the patient is already extubated from the ventilator, determine whether the patient's thinking is disorganized or incoherent, such as rambling or irrelevant conversation, unclear or illogical flow of ideas, or unpredictable switching from subject to subject.)

IV. Altered level of consciousness

Is the patient's level of consciousness anything other than alert, such as being vigilant or lethargic or in a stupor, or coma?

Alert: spontaneously fully aware of the environment and interacts appropriately Vigilant: hyperalert

Lethargic: drowsy but easily aroused, unaware of some elements in the environment or not spontaneously interacting with the interviewer; becomes fully aware and appropriately interactive when prodded minimally

Stupor: difficult to arouse, unaware of some or all elements in the environment or not spontaneously interacting with the interviewer; becomes incompletely aware when prodded strongly; can be aroused only by vigorous and repeated stimuli and as soon as the stimulus ceases, stuporous subject lapses back into an unresponsive state

Coma: unarousable, unaware of all elements in the environment with no spontaneous interaction or awareness of the interviewer so that the interview is impossible even with maximal proddingOverall CAM-ICU Assessment (Features 1 and 2 and either Feature 3 or 4): Yes No

*The authors stated that this table might be used without permission for clinical use only (Ely EW et al. JAMA 2001; 286:2703-2710).

mortality and increased health care costs [Mangusan 2015; Milbrandt 2004]. Vitamin D is a steroid hormone produced on the skin by the effect of sunlight, and it mainly plays a role in bone metabolism. It also is important for immunity, cardiovascular and central nervous systems [Roth 2018]. Vitamin D deficiency is a global problem, and many adults and infants have low vitamin D levels worldwide [Hilger 2014]. The active form of vitamin D, Calcitriol $(1,25$ dihydroxy vitamin D) is reported to reduce the oxidative stress in the central nervous system [Ibi 2001], and higher vitamin $\mathrm{D}$ levels are suggested to be protective for cognitive functions and also delirium [Bowman 2019].
In this study, we analyzed the association of preoperative vitamin $\mathrm{D}$ levels and postoperative delirium after cardiac surgery in patients over 65 years.

\section{MATERIALS AND METHOD}

Patients: After we received institutional review board approval, we retrospectively reviewed the data of 212 adult patients above 65 years of age who underwent isolated coronary artery bypass graft (CABG) surgery from January 2016 to January 2018. All patients previously had granted permission 
Table 2. Baseline and perioperative characteristics of patients

\begin{tabular}{lccc}
\hline Clinical characteristics & $\begin{array}{c}\text { Group 1* } \\
(\mathrm{N}=138)\end{array}$ & $\begin{array}{c}\text { Group 2** } \\
(\mathrm{N}=74)\end{array}$ & $P$ \\
\hline Age, years & $69.7 \pm 7.4$ & $70.6 \pm 4.8$ & .306 \\
Female, $\mathrm{n}$ & 112 & 45 & $.002 * *$ \\
Body mass index, kg/m² & $27.2 \pm 4.5$ & $27.9 \pm 5.2$ & .295 \\
Hypertension, $\mathrm{n}$ & 79 & 44 & .435 \\
Diabetes mellitus, $\mathrm{n}$ & 49 & 33 & .126 \\
Hyperlipidemia, $\mathrm{n}$ & 77 & 40 & .460 \\
CPB time, min & $101.2 \pm 33.8$ & $110.2 \pm 39.4$ & .083 \\
Cross-clamp time, min & $59.5 \pm 21.6$ & $61.2 \pm 20.75$ & .599 \\
LV function, \% & $54.4 \pm 9.6$ & $52.0 \pm 10.0$ & .087 \\
Serum creatinine, $\mathrm{mg} / \mathrm{dl}$ & $1.06 \pm 0.4$ & $0.99 \pm 0.3$ & .179 \\
Creatinine clearance, $\mathrm{ml} / \mathrm{min}$ & $84.1 \pm 32.2$ & $82.1 \pm 33.8$ & .675 \\
Euroscore II, \% & $3.7 \pm 2.6$ & $2.9 \pm 1.9$ & $.031 * * *$ \\
\hline
\end{tabular}

*Group I=patients with preoperative serum $25-\mathrm{OHD}$ levels $<25 \mathrm{nmol} / \mathrm{L}$,

$* *$ Group Il=patients with preoperative serum $25-\mathrm{OHD}$ levels $\geq 25 \mathrm{nmol} / \mathrm{L}$.

$* * * P<.05$, statistically significant.

for the use of their medical records for research purposes. The clinical data of the patients included demographic data, laboratory data, length of stay, in-hospital complications, and mortality. The patient population was divided into 2 groups based on preoperative serum vitamin D (25-hydroxyvitamin D [25-OHD]) levels (normal range of $25-75 \mathrm{nmol} / \mathrm{L}$ ). Group I included patients with preoperative serum 25-OHD level $<25 \mathrm{nmol} / \mathrm{L}$, and Group II included patients with preoperative serum 25 -OHD level $\geq 25 \mathrm{nmol} / \mathrm{L}$. The primary outcome was the development of postoperative delirium. Delirium was interpreted, according to the CAM-ICU scale [Ely 2001] for the assessment of delirium following cardiac surgery. (Table 1) Patients with a history of psychiatric disorder, preoperative dementia and history of cerebrovascular accident, and also patients undergoing operations other than or in conjunction with CABG were excluded from the study.

CABG Procedure: All operations were performed in a standardized approach by a Terumo roller pump (Terumo Advanced Perfusion System 1, USA) and membrane oxygenators (Inspire 8, LivaNova Sorin Group, Italy). Mild to moderate $\left(28-32^{\circ} \mathrm{C}\right)$ hypothermia and pulsatile flow of $2.2-2.4 \mathrm{~L} /$ $\mathrm{m} 2$ were used. Myocardial protection was achieved with tepid antegrade blood cardioplegia, and a "hot shot" (250ml-500 $\mathrm{ml}$ ) was delivered just before the removal of the aortic crossclamp. The perfusion pressure was kept over $70 \mathrm{mmHg}$ at all times. Induction and maintenance of general anesthesia with endotracheal intubation were standardized in all the patients (fentanyl, midazolam, and isoflurane in oxygen with air). The same surgical team performed all of the operations.

Postoperative management: Postoperatively, patients were followed in the intensive care unit (ICU), according to protocols of our institution. Electrocardiography, systemic mean
Table 3. Postoperative comparison of patients who developed postoperative delirium (POD) and no postoperative delirium (NPOD)

\begin{tabular}{lccc}
\hline & POD & NPOD & $P$ \\
\hline Mean ICU time $(\mathrm{h})^{*}$ & $64.5 \pm 31.3$ & $55.2 \pm 26.8$ & $.007 \dagger$ \\
IABP support $(\mathrm{n})^{*}$ & 10 & 7 & $.010 \dagger$ \\
Mean ventilatory support time $(\mathrm{h})^{*}$ & $11.8 \pm 17.3$ & $7.5 \pm 2.8$ & $.003 \dagger$ \\
In-hospital stay time $(\mathrm{d})^{*}$ & $7.4 \pm 2.7$ & $6.4 \pm 2.1$ & $.029 \dagger$ \\
30-day mortality $(\mathrm{n})^{*}$ & 6 & 2 & $.010 \dagger$ \\
\hline
\end{tabular}

*h: hours, IABP: intraaortic balloon pump, d: days, $\nmid P<.05$, statistically significant

arterial pressure, central venous pressure, pulmonary artery and wedge pressures, cardiac output and index, arterial blood gases, chest tube output, and hourly urine output were monitored. Serum electrolytes were measured in conjunction with arterial blood gas measurement. Fluid and electrolyte imbalances immediately were corrected with appropriate management. Hematocrit values $<25 \%$ were corrected with erythrocyte suspension administration. Daily blood urea nitrogen (BUN), serum and urea creatinine, and serum electrolytes uniformly were measured in all patients until discharge from the hospital. From postoperative day zero until discharge from the hospital, all patients were evaluated daily by the CAM-ICU scale. The screening was performed by educated nurses in ICU and the ward. CAM-ICU defines delirium by 4 features: 1) Acute onset of changes or fluctuations in the course of mental status; 2) Inattention; 3) Disorganized thinking; and 4) An altered level of consciousness. If the patients show both features of 1 and 2 and also an additional feature of 3 or 4, he or she is suggested to be in delirium [Ely 2001] (Table 1).

Statistical analysis: All statistics were performed using SPSS version 17.0 for Windows (IBM Corp., New York). Continuous variables were expressed as mean \pm SD and were compared by unpaired Student's t-test or chi-squared test. The effect of preoperative serum 25-OHD level on delirium after $\mathrm{CABG}$ was determined using logistic regression analysis, and the results were expressed as odds ratio (OR) with a $95 \%$ confidence interval (CI). A $P$-value $<.05$ was considered statistically significant.

\section{RESULTS}

In this study, 138 patients $(65.1 \%)$ had preoperative serum $25-\mathrm{OHD}$ levels $<25 \mathrm{nmol} / \mathrm{L}$, and 74 patients $(34.9 \%)$ had preoperative serum $25-\mathrm{OHD}$ levels $\geq 25 \mathrm{nmol} / \mathrm{L}$. Patient demographics and operative data are shown in Table 2. Preoperative patient characteristics and intraoperative data did not assure statistical significance between the 2 groups other than gender and Euro score. The preoperative mean serum 25-OHD was $19.1 \pm 4.4 \mathrm{nmol} / \mathrm{L}$ in Group I and 46.9 
$\pm 15.3 \mathrm{nmol} / \mathrm{L}$ in Group II $(P<.001)$. Preoperative mean serum 25-OHD levels significantly were lower in females than in males $(27.4 \pm 16.1 \mathrm{nmol} / \mathrm{L}$ and $32.9 . \pm 17.1 \mathrm{nmol} / \mathrm{L}$ respectively, $P=.032$ ) Euro score was found to be higher in Group I patients preoperatively than Group II $(3.7 \pm 2.6$ and $2.9 \pm 1.9$ respectively, $P=.031)$. The overall incidence of postoperative delirium was $30.2 \%$ and occurred in 48 patients (34.8\%) in Group I and 16 patients $(21.6 \%)$ in Group II, $P$ $=.032$. (Figure 1) On logistic regression analysis, the presence of lower serum 25-OHD levels preoperatively was shown to be associated with an increased incidence of postoperative delirium (OR:0.517, 95\% CI: 0.269-0.996, $P=.049$ ). Logistic regression analysis also revealed that the Euro score (OR: 1.135 95\% CI: $1.010-1.275, P=.033$ ) was the other independent risk factor for delirium after isolated CABG in this study. In our study, the prevalence of carotid artery stenosis (CAS) was found to be $25 \%(\mathrm{~N}=53)$. Of these patients with CAS in our study, $17 \%$ had $<50 \%$ degree of CAS, $6 \%$ had $50-69 \%$ stenosis, and $2 \%$ had $>70 \%$ stenosis. None of the patients studied had "near occlusion" or "total occlusion" of the carotid arteries.

Postoperatively, we compared the patients who developed postoperative delirium (POD) and no postoperative delirium (NPOD) (Table 3). The mean ICU time was $64.5 \pm 31.3$ hours in POD and $55.2 \pm 26.8$ hours in NPOD $(P=.007)$, in-hospital stay time was $7.4 \pm 2.7$ days in POD and $6.4 \pm 2.1$ days in NPOD $(P=.029)$. The intra-aortic balloon pump support was required in $8 \%$ of patients (10 patients in POD and 7 patients in NPOD, $P=.010)$. Prolonged ventilatory support was necessary for $4 \%$ of patients, and the mean ventilatory support time was $11.8 \pm 17.3$ hours in POD and $7.5 \pm 2.8$ hours in NPOD, $P=.003)$. Three patients in the POD group had sternal dehiscence managed with reoperation, and there was no mediastinitis in both the POD and NPOD groups. The 30-day mortality was $3.8 \%(\mathrm{~N}=8,6$ patients in POD and 2 patients in NPOD, $P=.010)$. All patients died due to low cardiac output and multiorgan failure.

\section{DIscussion}

The present study aimed to determine whether preoperative serum 25-OHD levels were associated with postoperative delirium after CABG. Our retrospective study illustrated that a lower preoperative serum level of 25-OHD was associated with postoperative delirium. Our results showed that $65.1 \%$ of patients had preoperative serum 25-OHD levels $<25 \mathrm{nmol} / \mathrm{L}$. It is known that vitamin $\mathrm{D}$ deficiency is present in $60-80 \%$ of patients upon admission to hospital in any kind of geographical setting [Zapatero 2018] thus our result was similar to literature. Hypovitaminosis D is common among older and critically ill patients [Borgermann 2012] and as we analyzed the cardiac surgical patients over 65 years of age, our results were also similar to literature in this regard.

The incidence of delirium after cardiac surgery varies between 3\%-67\% depending on how it is diagnosed [Gosselt 2015; Norkiene 2013]. In the present study, the incidence was found to be $30.2 \%$, which is diagnosed by
CAM-ICU that has high sensitivity and specificity. Delirium is reported to be associated with increased morbidity and even mortality after cardiac surgery [Norkiene 2013; Zhang 2013; Järvelä 2018]. It is reported that delirium increases the ICU stay times, stay in hospital, and eventually the costs [Järvelä 2018; Lundström 2005]. It also is suggested that delirium increased hospital mortality more than six-fold [Lundström 2005]. Our results revealed an increased ICU stay and hospital stay in patients with delirium that is in line with the studies in the literature [Järvelä 2018; Lundström 2005] (Table 3). In the present study, delirium increased 30-day mortality seven-fold $(P=.010)$, however, our results did not show a statistically significant difference between Group I vitamin D deficient patients and Group II with normal vitamin D levels regarding 30-day mortality $(P=.572)$.

Despite extensive research, the main pathophysiology of delirium remains unknown. Cardiopulmonary bypass (CPB) results in a systemic inflammatory response syndrome, and this is thought to result in fluid imbalance and microemboli eventually causing cerebral edema and resultant central nervous system problems such as confusion and delirium [Järvelä 2018; Bokeriia 2009]. In the systematic review by Gosselt et al [Gosselt 2015], the major risk factors for delirium were listed as age, preexisting cognitive disturbance, preoperative psychiatric condition, type of surgery, blood product transfusion, mechanical ventilation time, postoperative oxygen saturation, renal insufficiency, atrial fibrillation, and perioperative risperidone administration. Our study included patients undergoing $\mathrm{CABG}$ with $\mathrm{CPB}$ that are over 65 years of age, thus our study group had a higher risk of delirium. The American Geriatrics Society suggested in a recent practice guideline for patients aged over 65 years that prevention of delirium may be possible via frequent patient orientation, early mobilization, and rehabilitation [American Geriatrics Society Expert Panel 2015]. Some studies in the literature showed an increased risk of postoperative delirium associated with abnormal serum albumin, cobalamin deficiency, and high CRP and cortisol levels [Gosselt 2015; Lin 2012; Bakker 2012; Demirdas 2019]. Recently studies are dealing with the role of Vitamin D in cognitive functions. Additionally, it also is suggested that Vitamin D supplementation may play a protective role in neuropsychological disorders [Quraishi 2015; Annweiler 2009; Balion 2012]. Vitamin D receptors are present in the areas of cognition as the human cortex and hippocampus [Balion 2012]; it is reported that Vitamin D is important for nerve function and also upregulates the expression of neurotrophins from the hippocampus which are proteins responsible from the survival and maintenance of nerve cells [Braun 2014; McCann 2008]. Cardiac surgery with $\mathrm{CPB}$ results in a systemic inflammatory response and acute stress. Proinflammatory cytokines and chemokines are activated. One of the main pathophysiological hypotheses in delirium is the activation of the neuroinflammatory cascade in acute stress. Thus, it is plausible that deficiency in Vitamin D may contribute to delirium after cardiac surgery [Quraishi 2015]. Routine measurement of Vitamin D levels before cardiac surgery especially in patients over 65 years of age is suggested [Glade 2012], and we routinely have checked 
the preoperative levels of Vitamin D in our clinic since 2015. In the present study, logistic regression analysis stated that the presence of lower serum 25-OHD levels preoperatively was associated with an increased incidence of postoperative delirium after CABG with $\mathrm{CPB}$.

The other independent risk factor for delirium in our study was found to be increased Euro score. This result also is plausible that the Euro score is calculated, depending on patients' characteristics including age, renal functions, diabetes mellitus, and extracardiac arteriopathy. Older age, renal insufficiency, and cerebrovascular disease are the major risk factors for delirium confirming this association.

Preoperative carotid artery stenosis also is a major risk factor for delirium after cardiac surgery. In the present study the prevalence of preoperative CAS was $23.4 \%(\mathrm{~N}=15)$ in patients with POD and $25.6 \%(\mathrm{~N}=38)$ in patients with $\operatorname{NPOD}(P=.436)$.

Another finding in our study was the gender difference between the 2 groups. Vitamin D deficiency was more common among females in the present study. Quraishi et al [Quraishi 2015] also reported hypovitaminosis D in females in their study however Ford et al [Ford 2013] reported a higher prevalence of Vitamin D deficiency among men and made their argument based on the gender differences in the amount of body fat and/or its distribution.

\section{CONCLUSION}

In summary, the incidence of Vitamin D deficiency was $65.1 \%$, and the incidence of delirium was $30.2 \%$ in the present study. Vitamin D deficiency exacerbates delirium after $\mathrm{CABG}$ with $\mathrm{CPB}$. Whether the effects of vitamin $\mathrm{D}$ deficiency on this event represent separate or interrelated activities with $\mathrm{CPB}$ is an important question to be addressed and prospective randomized studies are necessary to confirm these results.

\section{REFERENCES}

American Geriatrics Society Expert Panel on Postoperative Delirium in Older Adults. 2015. Postoperative delirium in older adults: best practice statement from the American Geriatrics Society. J Am Coll Surg 220:136-148.

Annweiler C, Allali G, Allain P, et al. 2009. Vitamin D and cognitive performance in adults: a systematic review. Eur J Neurol. 16:1083-1089.

Bakker RC, Osse RJ, Tulen JH, et al. 2012. Preoperative and operative predictors of delirium after cardiac surgery in elderly patients. Eur J Cardiothorac Surg 41:544-549.

Balion C, Griffith LE, Strifler L, et al. 2012. Vitamin D, cognition, and dementia: a systematic review and meta-analysis. Neurology. 79:1397-1405.

Bokeriia LA, Golukhova EZ, Poluninia AG. 2009. Postoperative delirium in cardiac operations: Microembolic load is an important factor. Ann Thorac Surg 88: 348-354.

Borgermann J, Lazouski K, Kuhn J, Dreier J, Schmidt M, GilisJanuszewski T, et al. 2012. 1,25-dihydroxy vitamin D fluctuations in cardiac surgery are related to age and clinical outcome. Crit Care Med 40(7):2073e81.

Bowman K, Jones L, Pilling LC, Delgado J, Kuchel GA, Ferrucci L, Fortinsky RH, Melzer D. 2019. Vitamin D levels and risk of delirium: A mendelian randomization study in the UK Biobank. Neurology 92(12): e1387-e1394.

Braun LA, Spitzer O, Levkovich B, Bailey M, Stanguts C, Hose L, Rosenfeldt F. 2014. Prevalence of vitamin D deficiency prior to cardiothoracic surgery. Heart Lung Circ 23(10):978-80.

Cropsey C, Kennedy J, Han J, Pandharipande P. 2015. Cognitive Dysfunction, Delirium, and Stroke in Cardiac Surgery Patients. Semin Cardiothorac Vasc Anesth 19:309-17.

Demirdas E, Atilgan K. 2019. Addition of Vitamin B Complex to Prime Solution in Cobalamin-Deficient Patients to Prevent Postoperative Delirium. Heart Surg Forum. 25;22(2): E082-E087.

Ely EW, Inouye SK, Bernard GR, Gordon S, Francis J, May L, Truman B, Speroff T, Gautam S, Margolin R, Hart RP, Dittus R. 2001. Delirium in mechanically ventilated patients: validity and reliability of the confusion assessment method for the intensive care unit (CAM-ICU). JAMA. 286:2703-10.

European Delirium Association and American Delirium Society. 2014. The DSM-5 criteria, level of arousal and delirium diagnosis: inclusiveness is safer. BMC Medicine 12:141.

Ford J, Hategan A, Bourgeois JA, Tisi DK, Xiong GL. 2013. Hypovitaminosis D in delirium: a retrospective cross-sectional study. Can Geriatr J 16:186-91.

Glade MJ. 2012. A 21st-century evaluation of the safety of oral vitamin D. Nutrition. 28:344-356.

Gosselt AN, Slooter AJ, Boere PR, Zaal IJ. 2015. Risk factors for delirium after on-pump cardiac surgery: a systematic review. Crit Care 19:346.

Grover S, Kate N. 2012. Assessment scales for delirium: A review. World J Psychiatr 2:58-70.

Hilger J, Friedel A, Herr R, et al. 2014. Br. J. Nutr. 111, 23-45; Palacios C, Gonzalez L, 2014. J. Steroid Biochem. Mol. Biol. 144, 138-145.

Ibi M, Sawada H, Nakanishi M, et al. 2001. Protective effects of 1 alpha,25-(OH)2D3 against the neurotoxicity of glutamate and reactive oxygen species in mesencephalic culture. Neuropharmacol 40(6):761-71.

Järvelä K, Porkkala H, Karlsson S, Martikainen T, Selander T, Bendel S. 2018. Postoperative Delirium in Cardiac Surgery Patients. J Cardiothorac Vasc Anesth 32:1597-1602.

Lin Y, Chen J, Wang Z. 2012. Meta-analysis of factors which influence delirium following cardiac surgery. J Card Surg 27:481-492.

Lundström M, Edlund A, Karlsson S, et al. 2005. A multifactorial intervention program reduces the duration of delirium, length of hospitalization, and mortality in delirious patients. J Am Geriatr Soc 53: 622-628.

Mangusan RF, Hooper V, Denslow SA, Travis L. 2015. Outcomes associated with postoperative delirium after cardiac surgery. Am J Crit Care 24:156-63.

McCann JC, Ames BN. 2008. Is there convincing biological or behavioral evidence linking vitamin D deficiency to brain dysfunction? FASEB J. 22:982-1001.

Milbrandt EB, Deppen S, Harrison PL, Shintani AK, Speroff T, Stiles RA, et al. 2004. Costs associated with delirium in mechanically ventilated patients. Crit Care Med 32:955-62. 
Norkiene I, Ringaitiene D, Kuzminskaite V, Sipylaite J. 2013. Incidence and risk factors of early delirium after cardiac surgery. Biomed Res Int 323491.

Quraishi SA, Litonjua AA, Elias KM, Gibbons FK, Giovannucci E, Camargo CA Jr, Christopher KB. 2015. Association between prehospital vitamin $\mathrm{D}$ status and hospital-acquired new-onset delirium. Br J Nutr. 113(11):1753-60.

Roth DE, Abrams SA, Aloia J, Bergeron G, Bourassa MW, Brown KH, Calvo MS, Cashman KD, Combs G, De-Regil LM, Jefferds ME, Jones KS, Kapner H, Martineau AR, Neufeld LM, Schleicher RL, Thacher
TD, Whiting SJ. 2018. Global prevalence and disease burden of vitamin D deficiency: a roadmap for action in low- and middle-income countries. Ann N Y Acad Sci 1430(1):44-79.

Zapatero A, Dot I, Diaz Y, Gracia MP, Pérez-Terán P, Climent C, et al. 2018. La hipovitaminosis D grave al ingreso en el paciente crítico se asocia a fracaso renal agudo y mal pronóstico. Med Intensiva 42:216-224.

Zhang Z, Pan L, and Ni H. 2013. Impact of delirium on clinical outcome in critically ill patients: a meta-analysis. General Hospital Psychiatry vol. 35 , pp. $105-111$. 